\title{
DESAPARICIONES FORZADAS E IMPUNIDAD EN LA HISTORIA MEXICANA RECIENTE*
}

\author{
Silvia Dutrénit Bielous ${ }^{(a)}$ y Gonzalo Varela Petito(b)
}

FORCED DISAPPEARANCES AND IMPUNITY IN RECENT MEXICAN HISTORY

DESAPARECIMENTOS FORÇADOS E IMPUNIDADE

NA HISTÓRIA MEXICANA RECENTE

Fecha de recepción: 10 de septiembre del 2017

Fecha de aprobación: 7 de diciembre del 2017

\section{Sugerencia de citación:}

Dutrénit Bielous, S., y Varela Petito, G. (2018). Desapariciones forzadas e impunidad en la historia mexicana reciente. Razón Crítica, 4, 105-135, doi: http://dx.doi.org/10.21789/25007807.1300

* El artículo se realizó como parte de las actividades del proyecto CONACYT-Mora (clave CB 2012/177295). El trabajo de los equipos de antropología forense en América Latina: otra ruta de acceso al conocimiento de la represión y violencia políticas.

(a) Instituto Mora-CONACyT, México

https://orcid.org/0000-0002-4485-4601 sdutrenit@hotmail.com

(b) Universidad Autónoma Metropolitana, unidad Xochimilco, México

https://orcid.org/0000-0002-5648-6332 lombardi60@gmail.com 


\section{R E S U M E N}

En 2014, la desaparición de 43 estudiantes de una escuela normal rural en Ayotzinapa, Guerrero, hizo evidente al mundo la práctica del delito de desaparición forzada en México. Desde décadas atrás se habían producido acontecimientos similares, lo que devino en una sentencia en 2009 al Estado mexicano por parte de la Corte Interamericana de Derechos Humanos (CoIDH) en relación con el llamado Caso Rosendo Radilla. Mecanismos de impunidad muy estructurados han impedido evitar o dilucidar resolver estos crímenes.

PALABRAS CLAVE: México, derechos humanos, desaparición forzosa, impunidad, Ayotzinapa. 


\section{A B S T R A C T}

In 2014 the disappearance of 43 students from a rural school in Ayotzinapa, Guerrero, showed evidence to the world of the continuous practice of the crime of forced disappearance in Mexico. From decades back similar events had occurred, which led the Inter-American Court of Human Rights (IACHR) to sentence Mexico in the 2009 case known as Rosendo Radilla. However, deeply structured impunity mechanisms have impeded the prevention or elucidation of these crimes.

\section{KEY WORDS: Mexico, human rights, forced disappearance, impunity, Ayotzinapa.}

\section{R E S U M O}

Em 2014, o desaparecimento de 43 alunos de uma escola rural normal em Ayotzinapa, Guerrero, evidenciou ao mundo a prática do crime de desaparecimento forçado no México. Há décadas, vinham ocorrendo eventos semelhantes, o que resultou numa sentença em 2009 para o Estado mexicano, por parte da Corte Interamericana de Direitos Humanos, quanto ao chamado caso Rosendo Radilla. Mecanismos de impunidade muito estruturados impediram que esses crimes fossem evitados ou resolvidos.

PALAVRAS-CHAVE: Ayotzinapa, desaparecimento forçado, direitos humanos, impunidade, México. 


\section{N T R O D U C C I Ó N}

En 2014, la desaparición en la ciudad de Iguala de 43 estudiantes de una escuela normal rural de Ayotzinapa, en el estado de Guerrero -una de las zonas de México donde han desaparecido muchas otras personas- exhibió como nunca la grave reiteración de este delito en México. Anteriormente, la resolución de la Corte Interamericana de Derechos Humanos (en adelante CoIDH) por el llamado caso Rosendo Radilla ${ }^{1}$ apenas si había logrado atraer la atención sobre las desapariciones forzadas de los años de 1970 y 1980. En cambio, las impugnaciones por el caso Ayotzinapa hicieron que el Estado mexicano sufriera una grave crisis de credibilidad en los ámbitos nacional e internacional. El último informe del Grupo Internacional de Expertos Independientes (en adelante GIEI), creado en la órbita de la Comisión Interamericana de Derechos Humanos (en adelante CIDH) a propósito de la desaparición de los normalistas, aunque sin carácter de sentencia, confirmó de manera directa y documentada las observaciones del órgano interamericano al Estado mexicano concernientes a derechos humanos (GIEI, 2016).

Si la sentencia Radilla no fue suficiente para presentar en el foro global la imagen de un Estado que atentaba o encubría delitos contra los derechos humanos, Ayotzinapa, en un entorno nacional de adhesión a la tratadística sobre Derechos Humanos (DD. HH.) y construcción de instituciones especializadas en la materia,

1 Véase en las siguientes páginas. 
determinó que, por acción u omisión, la comisión de delitos de lesa humanidad, como la desaparición forzada, generó una situación de emergencia, como puede advertirse en las recomendaciones del Comité contra las Desapariciones Forzadas de la Organización de Naciones Unidas (ONU) emitidas en 2015. Este Comité exhortó a las autoridades de México a tomar medidas para cumplir con sus obligaciones como Estado signatario de la Convención Internacional sobre el tema. ${ }^{2}$ En su informe final, indica que México vive un contexto de desapariciones generalizadas en gran parte de su territorio, muchas de las cuales podrían calificarse de forzadas. Se pronuncia también sobre los serios desafíos que enfrenta el país en materia de prevención, investigación y sanción de este tipo de delito, así como en la búsqueda de personas desaparecidas. Igualmente, recomendó crear un registro nacional único de personas desaparecidas e intensificar los esfuerzos para prevenir e investigar las desapariciones de migrantes en tránsito por su territorio (Centro de Derechos Humanos Miguel Agustín Pro Juárez et ál., 2015).

Sin embargo, se observa una política ambigua y una estrategia confusa en el campo de la defensa y promoción de los derechos humanos, que conduce a una difícil relación con el Sistema Interamericano de Derechos Humanos (en adelante SIDH) y con la Organización de Naciones Unidas, lo que provocó, incluso, fricciones con un relator especial de este último organismo sobre el tema de la tortura ${ }^{3}$.

La vigencia de la impunidad genera una crisis por la que se cierran los caminos a las instituciones nacionales puestas en pie para satisfacer la demanda de verdad y justicia, y se fomenta indirectamente que víctimas o terceros en discordia recurran, a falta de otra alternativa, a las instancias especializadas internacionales en la materia.

2 Ante la exigencia de la sociedad civil respecto a que el comité pueda recibir y examinar casos individuales de desapariciones forzadas, presentadas de manera directa por los ciudadanos, este órgano emitió recomendaciones en que se "alienta enérgicamente" al Estado a reconocer la facultad para que los expertos de la onu puedan revisar casos (Comité contra la Desaparición Forzada, 2015).

3 En el caso de la onu, véase el Informe del relator especial Juan Méndez, en donde señala que "La tortura es generalizada en México. Ocurre especialmente desde la detención y hasta la puesta a disposición de la justicia, y con fines de castigo e investigación" (ONU, 2014). Ello despertó la reacción del gobierno mexicano, que por cuestión de "agenda" no permitió que regresara en misión durante 2016 a realizar otra visita que solicitara desde 2015 (Gómez, 2016). 
Ayotzinapa puso en evidencia que muchas de las reiteradas desapariciones realizadas bajo similares condiciones de impunidad habían quedado fuera del foco de atención de la opinión pública global. En ese sentido, como se sostiene a continuación, la información existente revela que el hecho es reiterado, a lo largo de los últimos cincuenta años, y se mantiene con grados de mayor a menor invisibilidad desde la década del sesenta del siglo pasado hasta que estalló el caso de Ayotzinapa. Así mismo, es posible apreciar cómo se activan mecanismos de impunidad y cómo, a medida que se crean y desarrollan estructuras institucionales destinadas a develar violaciones de derechos humanos, se produce un conflicto cada vez más público a causa de la omisión de investigación y procuración de justicia, lo que deriva en denuncias como procesos jurisdiccionales en organismos nacionales e internacionales.

Con la perspectiva de la historia reciente que entreteje miradas disciplinarias provenientes del derecho, la ciencia política y las relaciones internacionales, este artículo busca examinar las características de impunidad que han afectado la práctica del Estado mexicano en materia de violaciones de derechos humanos. Las fuentes usadas para respaldar los hechos narrados responden a la existencia cada vez mayor de documentación jurídica que informa de dichas situaciones de impunidad. Al mismo tiempo, se incorporan un conjunto de informaciones hemerográficas sobre aspectos puntuales de la narración.

El artículo comprende cinco secciones. La primera, de manera sintética, reconstruye las bases de la impunidad en relación con la forma en que el sistema político ha limitado e, incluso, impedido que se cumplan las funciones estatales relativas a la defensa de los derechos humanos de sus ciudadanos. Abarca desde mediados de los años sesenta del siglo pasado hasta el presente. En la segunda sección se aborda de manera particular el procesamiento de las violaciones a los derechos humanos a partir del reconocimiento explícito que hizo el Informe Especial de la Comisión Nacional de Derechos Humanos (en adelante CNDH) en noviembre de 2001. En la tercera sección se exponen, más específicamente y basados en la sentencia de la CoIDH sobre el caso Rosendo Radilla, las formas que adquirió el ejercicio de la impunidad durante y después de los años setenta, cuando se desplegó la represión política sobre los 
movimientos campesinos y sociales. Este momento marca también el inicio de la intervención de las instancias internacionales para investigar y dirimir responsabilidades ante la ausencia del cumplimiento de las obligaciones estatales en materia de protección de los derechos humanos. La cuarta sección muestra lo que se visibilizó en el foro global acerca del acontecimiento de Ayotzinapa. En particular, se percibe, mediante la documentación generada por expertos internacionales y testigos, la trama de una remozada impunidad y el papel de un Estado que resulta cuestionado por los organismos internacionales intervinientes. La sección quinta es de conclusión.

\section{Estado y fuentes de la impunidad}

De acuerdo con particularidades de su desarrollo histórico y de su sistema político, durante el periodo de la guerra fría en México se pusieron en práctica tanto estrategias sui generis de abordaje de situaciones de conflicto interno, como de relaciones internacionales. No obstante que durante el predominio hegemónico del Partido Revolucionario Institucional (PRI) el gobierno mexicano, a diferencia de otros de la región latinoamericana, mantuviera muy buenas relaciones diplomáticas con la Unión Soviética y el gobierno de Cuba, desde 1959 en declaraciones oficiales aflora la preocupación de que los "ejemplos de luchas o de pueblos lejanos y distintos al nuestro" (Secretaría de la Presidencia, 1976, p. 349) ${ }^{4}$ se hicieran sentir en el país, inspirando movimientos que buscaran cambiar el orden político y económico existente. El hecho mismo de la relativa proximidad en el tiempo de la revolución mexicana de 1910-1917 y, en especial, su elogio y recuerdo permanentes en la retórica oficial, servía contradictoriamente para alimentar en el imaginario popular el espíritu insurgente. Por lo demás, el acelerado cambio socioeconómico de México en la posguerra, con una progresiva integración a la economía estadounidense junto al mantenimiento o surgimiento de profundas brechas de desigualdad social, así como el descontento de grupos intelectuales con el sistema de autoritarismo "blando" (ya no tan blando luego de la represión

4 Palabras del presidente Adolfo López Mateos (1958-1964). 
masiva de 1968) hizo que al igual que en otros países de América Latina, aunque por razones nacionales propias, surgieran en los años setenta del siglo XX movimientos guerrilleros, ya sea de base urbana o de implantación rural, particularmente en el estado de Guerrero, con altos índices de atraso económico y disparidad social. ${ }^{5}$

Las peculiaridades del sistema político mexicano, que no apelaba prioritariamente a esquemas represivos (si bien estos no faltaban), sino a mecanismos de control corporativo de masas y estaban acompañados de un discurso progresista, determinaron la respuesta dada a este desafío. Sobre todo, en el periodo posterior a 1971, la orientación gubernamental fue por un lado de tolerancia e incluso apertura de espacios de expresión y organización para grupos intelectuales, movimientos estudiantiles y organizaciones de izquierda con perspectiva crítica, pero predominantemente pacífica; por otro lado, la represión policial y militar se desató implacablemente contra los movimientos armados contestatarios y, aunque no llamara tanto la atención en ese momento, también en las zonas rurales en que el narcotráfico expandía sus redes sociales para la producción y traslado de drogas (con el nombre clave de Operación Cóndor). ${ }^{5}$ Por lo que se sabe, con base en testimonios e investigaciones oficiales o independientes, estas campañas se acomodaban, en términos generales, al formato de la llamada "guerra sucia" contrainsurgente, con su secuela de torturas, prisiones y ejecuciones clandestinas, desapariciones forzadas y amenazas o represalias contra comunidades que real o presuntamente apoyaran a los grupos objetivo de la represión. ${ }^{6}$ Aparte de estas circunstancias

\footnotetext{
$5 \quad \mathrm{Al}$ descubrirse los Archivos del Terror en Asunción, Paraguay, se rescataron documentos referentes a la Operación Cóndor. Entre los documentos se halló una carta que daba cuenta de la reunión organizada por la Confederación Anticomunista Latinoamericana (CAL), que fue realizada en Guadalajara, México, entre el 10 y el 14 de julio de 1974. En esa reunión se resolvió establecer "un sistema de información para intercambiar datos y establecer una agencia de noticias para apoyar a los gobiernos nacionalistas y denunciar las actividades marxistas" (Rodríguez Tovar, 2002). Sobre la ultraderecha de Guadalajara y la relación internacional, se recomienda consultar los artículos de Mónica López Macedonio (2010) y de María Guadalupe Moreno González (2017). Asimismo, se debe considerar que la Operación Cóndor (1975-1978) resultó un ensayo inaugural de la estrategia antidroga dirigida por militares (Astorga, 2007, p. 12 y capítulo 2).

6 No obstante su uso corriente, el término "«guerra sucia"» ha sido cuestionado por las víctimas en virtud de que da la idea de una confrontación entre fuerzas equivalentes (movimiento armado/guerrilla-ejército) e «invisibiliza la manera en que el Estado utilizó sus medios e instituciones para reprimir a los movimientos disidentes o a quienes fueran considerados como bases de apoyo de estos, como en el caso de Guerrero". (Centro de Derechos Humanos Miguel Agustín Pro Juárez et ál, (2014).
} 
coyunturales, tales actuaciones tenían sustento en un contexto jurídico y político de largo plazo en que las fuerzas de seguridad se consideraban libres de rendir cuentas en asuntos de derechos humanos y, en lo que respecta a las fuerzas armadas, libres de todo cuestionamiento en términos generales.

Simultáneamente el gobierno mexicano predicaba el tercermundismo, la no alineación con las grandes potencias y, yendo más allá de la Doctrina Estrada de no opinar sobre otros países, condenaba a la dictadura militar chilena y ejercía una política diplomática de asilo y refugio de perseguidos por motivos políticos en países del Cono Sur latinoamericano ${ }^{7}$. Víctimas de autoritarismos lejanos encontraban así amparo en el territorio nacional, mientras se reprimía sin limitaciones a parte de la oposición interna.

Hay en tal sentido evidencia documentada de actos de detención, tortura y desaparición de personas por parte de agentes del Estado que configuran delitos de lesa humanidad ${ }^{8}$. La Fiscalía Especial para Movimientos Sociales y Políticos del Pasado (en adelante FEMOSPP), creada ex profeso en 2002 para investigar y determinar violaciones de derechos humanos cometidas por agentes del Estado o a su amparo, especificó:

7 Acerca de la política y práctica de asilo en México en aquellos años, pueden consultarse algunos de los siguientes estudios: S. Dutrénit (2011), G. Martínez Corbalá (1998) y F. Serrano Migallón (1998)

8 Sobre la necesidad de investigar ese tramo de la historia reciente mexicana, la CNDH lo registró en su informe especial de noviembre de 2001 (CNDH, 2001). Antes y después de ese hito, en virtud de la convocatoria que realizada la $\mathrm{CNDH}$, documentos y testimonios daban cuenta de esa consideración. Lo mismo ocurrió con el informe producido por la Fiscalía Especial para Movimientos Políticos del Pasado (FEMOSPP) de 2007, titulado Informe histórico presentado a la sociedad mexicana: Fiscalía especial FEMOSPP. Pese a lo recortado del mismo, ratificaba con evidencias las violaciones ocurridas. Véase en particular el informe (conocido como borrador) que se filtró y fue recuperado por The Nacional Security Archive (FEMOSPP, 2006). Otras rutas de información por conducto de la prensa son elocuentes. Por ejemplo, "el expediente de la Dirección General de Policía y Tránsito del Distrito Federal (DGPTDF) encontrado por La Jornada es una bitácora oficial de un momento de la guerra sucia de los años 70. Ahí se registran 27 bajas de la Liga Comunista 23 de Septiembre ocurridas entre abril y agosto de 1975 en el Distrito Federal y Morelos. Es el fragmento de una historia que se quiso borrar de los archivos. Cada página del legajo recoge parte de la memoria del horror que fue la guerra ilegal que libró el Estado mexicano contra la guerrilla. La información contenida en el documento fue arrancada a los detenidos bajo tortura. Así lo prueban los testimonios de algunos de ellos y los informes que sobre esas "confesiones" elaboró el capitán Luis de la Barreda Moreno, entonces director de la Dirección Federal de Seguridad (DFS), y que entregó a la Secretaría de Gobernación, cuyo titular era Mario Moya Palencia. Esos informes, cuya copia tiene este diario, están en el Archivo General de la Nación" (Ramírez, 2005). 
Al concluir esta investigación se constata que el régimen autoritario, a los más altos niveles de mando, impidió, criminalizó y combatió a diversos sectores de la población que se organizaron para exigir mayor participación democrática en las decisiones que les afectaban, y de aquellos que quisieron poner coto al autoritarismo, al patrimonialismo, a las estructuras de mediación y a la opresión. El combate que el Estado emprendió en contra de estos grupos nacionales -que se organizaron en los movimientos estudiantiles, y en la insurgencia popular- se salió del marco legal e incurrió en crímenes de lesa humanidad que culminaron en masacres, desapariciones forzadas, tortura sistemática, crímenes de guerra y genocidio al intentar destruir a este sector de la sociedad al que consideró ideológicamente como su enemigo. (National Security Archive, 2006)

Otras violaciones de derechos humanos siguieron acaeciendo en etapas posteriores, lo que ha motivado ocho sentencias de la COIDH dirigidas al Estado mexicano ${ }^{9}$.

Tal práctica sin garantías, que contradice preceptos constitucionales y legales hace tiempo consagrados, empezó a ser cada vez más objeto de crítica pública a partir de las dos últimas

9 Estas son: 1) García Cruz y Sánchez Silvestre Vs. Estados Unidos Mexicanos, 2013. Referida a la detención de los señores García Cruz y Sánchez Silvestre, quienes posteriormente fueron sometidos a tortura para obtener una confesión por los cargos imputados en su contra. 2) Caso Rosendo Cantú y otra Vs. México, 2010. Relativa al acto de violación sexual de la señora Rosendo Cantú cometida por dos militares en presencia de otros seis. 3) Caso Fernández Ortega y otros Vs. México, 2010. Justificada en la responsabilidad internacional del Estado por la violación sexual cometida en perjuicio de Inés Fernández Ortega por parte de agentes militares, así como por la falta de investigación y sanción de los responsables. 4) Caso Cabrera García y Montiel Flores Vs. México, 2010. Se asienta en la responsabilidad internacional del Estado por la detención arbitraria y tratos crueles y degradantes a los que fueron sometidos Teodoro Cabrera García y Rodolfo Montiel Flores, así como por la falta de investigación y sanción de los responsables. 5) Caso Radilla Pacheco Vs. México, 2009. Se basa en la responsabilidad internacional del Estado por la desaparición forzada de Rosendo Radilla Pacheco por parte de las Fuerzas Armadas Mexicanas, así como por la falta de investigación y sanción de los responsables. 6) Caso González y otras (Campo Algodonero) Vs. México, 2009. Se asienta en la responsabilidad internacional del Estado por la falta de diligencia en las investigaciones relacionadas a la desaparición y muerte de Claudia Ivette Gonzáles, Esmeralda Herrera Monreal y Laura Berenice Ramos Monárrez. 7) Caso Castañeda Gutman Vs. México, 2008. Relativa a la responsabilidad internacional del Estado por la inexistencia de un recurso adecuado y efectivo en relación con el impedimento de Jorge Castañeda Gutman para inscribir su candidatura independiente a la Presidencia de México. 8) Caso Alfonso Martín del Campo Dodd Vs. México, 2004. Se asienta en el archivamiento del caso por la falta de competencia ratione temporis de la CoIDH en relación a los presuntos actos de tortura cometidos en contra de Alfonso Martín del Campo Dodd con el objetivo de confesar un crimen de homicidio (COIDH, s. f.). 
décadas del siglo xx, época en que el gobierno emprendió una radical iniciativa de apertura económica y, por lo mismo, se volvió susceptible a las presiones internas y externas que le obligaban a readecuar su sistema político por el camino de la democratización, uno de cuyos capítulos sería la cultura de los derechos humanos (Dutrénit y Varela, 2010). Pero fue especialmente en 2009, a raíz de la sentencia de la COIDH en contra el Estado mexicano por el Caso Rosendo Radilla, que el tema de la desaparición forzada y sus víctimas cobrara relativa visibilidad, impulsando una reforma de la administración de justicia que excluyó al fuero castrense del juzgamiento de acusaciones por violaciones de derechos humanos imputadas a alguno de sus integrantes ${ }^{10}$. Estas reformas emprendidas por el gobierno mexicano trascendieron a nivel internacional y alcanzaron reconocimiento de la ONU ${ }^{11}$. Para entonces, la desaparición forzada de personas por diversas causas (no solo políticas), así como otros atentados contra seres humanos, ante una evidente inoperatividad del Estado para aclarar la información e impartir justicia, se convirtieron en objeto de denuncia cada vez más numerosa, incrementada a la luz de la nueva guerra desatada desde 2006 contra el narcotráfico ${ }^{12}$.

10 En julio de 2011 finalizó el estudio, por parte del Estado mexicano, de la resolución de la COIDH y confirmó la restricción del fuero militar en las situaciones que afecten los DD. HH. de civiles. En abril de 2014 el Senado aprobó la reforma que restringe el fuero militar. Hay que recordar que la estructura de impartición de justicia mexicana ha sido muy cuestionada y aún más si se considera que en situaciones extremas, como las demandas originadas en violaciones cometidas por militares, en las que eran juzgados castrenses quienes las recibían y tramitaban.

11 En ese sentido, debe considerarse que fue en noviembre de 2013, cuando que una noticia se extendió por los medios de comunicación: el registro de los expedientes vinculados al caso Radilla de la SCJN pasó a integrar el Programa de Memoria del Mundo de la Organización de las Naciones Unidas para la Educación, la Ciencia y la Cultura (UNESCO). Resulta sin duda un hecho significativo por quien debido al organismo que otorga tal reconocimiento, a la vez que se constituye en parte de un acervo de la humanidad junto a otros registros trascendentes y de distinta índole, como lo son entre otros, el archivo de la construcción y caída del Muro de Berlín, el proceso penal del Estado contra Nelson Mandela (253/1963) y el Diario de Ana Frank. Se trata de un reconocimiento a la SCJN referida al expediente “«arios” $912 / 2010$, en donde se ubica la determinación de obligatoriedad de las sentencias de COIDH para el Estado mexicano en general y, por ende, para el Poder Judicial en particular, por las graves violaciones de los DD. HH. cometidas contra Rosendo Radilla. Esta situación devino en el establecimiento de los lineamientos para atender las medidas de reparación sugeridas al Poder Judicial de la Federación (CNN, 2013). A los pocos días de ese reconocimiento, la ONU anunció que la SCJN fue seleccionada entre los ganadores del Premio 2013 de Derechos Humanos. Se indicó que el premio se otorgaba debido a que la SCJN alcanzó “" "importantes progresos" en la promoción de los derechos humanos a través de sus interpretaciones y de la aplicación de la Constitución mexicana y sus obligaciones bajo el derecho internacional en la materia”", (NOTIMEX, 2013).

12 La Convención Interamericana sobre Desaparición Forzada de Personas entró en 


\section{El Estado culposo: la formación de la FEMOSPP}

De este modo, una abultada lista de víctimas de desaparición forzada a causa de la represión política o del crimen organizado hace que por tiempo prolongado el destino de los directa o indirectamente afectados se mantenga en la incertidumbre y los responsables continúen impunes ${ }^{13}$. La mención sobre la participación de agentes oficiales en tales hechos ha sido permanente y creciente en las últimas décadas. Un Estado de derecho proclamado como tal debería aportar información y debido juicio a los culpables, siendo esta la principal reparación para las víctimas y sus familiares (no menos victimizados). Como ha señalado la COIDH, "la privación continua de la verdad acerca del destino de un desaparecido constituye una forma de trato cruel e inhumano para los familiares cercanos" (2009). Este tribunal considera, además, que tal derecho no solo asiste a las víctimas directas e indirectas, sino también a la sociedad en general, en la medida en que se violan importantes instrumentos internacionales atinentes al Derecho Internacional Humanitario y a la Corte Interamericana de Derechos Humanos (COIDH, 2000).

Al respecto, la "guerra sucia" desarrollada en México, en el marco de la guerra fría, dejó entre los años sesenta y ochenta

\footnotetext{
vigor en 1996. Posteriormente, la Oficina del Alto Comisionado de las Naciones Unidas para los Derechos Humanos revisó el instrumento y aprobó, en 2006, la Convención Internacional para la Protección de todas las Personas contra las Desapariciones Forzadas. Entre sus artículos principales se encuentran: Artículo 2A. Para los efectos de la presente Convención, se entenderá por "desaparición forzada” el arresto, la detención, el secuestro o cualquier otra forma de privación de libertad que sean obra de agentes del Estado o por personas o grupos de personas que actúan con la autorización, el apoyo o la aquiescencia del Estado, seguida de la negativa a reconocer dicha privación de libertad o del ocultamiento de la suerte o el paradero de la persona desaparecida, sustrayéndola a la protección de la ley. Artículo 3. Los Estados Partes tomarán las medidas apropiadas para investigar sobre las conductas definidas en el que sean obra de personas o grupos de personas que actúen sin la autorización, el apoyo o la aquiescencia del Estado, y para procesar a los responsables. Artículo 4. Cada Estado Parte tomará las medidas necesarias para que la desaparición forzada sea tipificada como delito en su legislación penal. Artículo 5. La práctica generalizada o sistemática de la desaparición forzada constituye un crimen de lesa humanidad, tal como está definido en el derecho internacional aplicable y entraña las consecuencias previstas por el derecho internacional aplicable". (Oficina del Alto Comisionado de las Naciones Unidas para los Derechos Humanos, 2006, 2009).

13 Consúltese el Índice Global de Impunidad - México, 2016 (LeClercq y Rodríguez, 2016).
} 
cifras de afectaciones cuya estimación difiere si se compara con las denuncias realizadas. Hay que tener en cuenta que se modifican con el tiempo e influyen en la concreción de las denuncias los retos emocionales y prácticos por dolor y temor a represalias, así como la credibilidad en las instituciones. Por ejemplo, la Asociación de Familiares de Detenidos Desaparecidos y Víctimas de Violaciones a los Derechos Humanos en México (AFADEM) registra un número de 609 desapariciones forzadas solo para el estado de Guerrero (Sánchez Serrano, 2014, p. 261) ${ }^{14}$. En cambio, el Informe de la CNDH entregado al presidente Fox en noviembre de 2001 indica que se recibieron 482 denuncias (GNDH, 2001). Este saldo aproxima a México al desempeño represivo de otros gobiernos latinoamericanos en la misma época, con la diferencia de que los segundos eran dictaduras. Dadas las peculiaridades ya explicadas, estos hechos en México respondieron a una estrategia represiva del Estado en respuesta a presiones y demandas de diferentes sectores sociales u organizaciones políticas. Se trató de una acción centrada sobre todo en el ámbito rural (Sánchez Serrano, Ferrer Vicario, Rangel Lozano, Aréstegui Ruiz, y Solís Téllez, 2014) pero que abarcó también las urbes, como muestra lo sucedido en relación con el movimiento estudiantil de los años de 1968 y 1971 y con los movimientos armados, en especial en ciudades como Guadalajara y Monterrey (Montemayor, 2010; Castellanos, 2008). En un contexto de restricción de la prensa y conformismo de la opinión pública, así como de pasividad de masas de trabajadores encuadradas en organizaciones corporativas del Estado, los acontecimientos eran parcial o totalmente desconocidos, tergiversados o disminuidos en su impacto. Mucho de lo que pudiera suceder especialmente en la periferia campesina resultaba inexistente en el espacio público de una república de por sí muy centralista.

Toda aguda manifestación discordante en esta época era juzgada como desestabilizadora por un régimen muy afianzado que, de trascender un acto notorio de represión, lo traducía como mal necesario para protegerse de los enemigos de la nación. La justicia se procuraba e impartía bajo un estricto control del ejecutivo y eran

14 Una publicación de Claudia Rangel registra la cifra de 650 desaparecidos en Guerrero y 473 en Atoyac de Álvarez, municipio de ese estado mexicano (2012, p. 85). 
funcionales a dicha estrategia, por lo que las denuncias de graves violaciones de derechos humanos no tenían serias posibilidades de lograr la puesta en marcha de investigaciones eficaces. El largo proceso de la denuncia del caso Radilla es emblemático de estas circunstancias (Dutrénit, 2014, pp. 81-87; Sánchez Serrano, 2014, pp. 255-258).

Al finalizar el siglo xx, algunos sectores oficiales comenzaron a quebrantar el silencio, pero solo como tropo memorístico, sin que mutaran las estructuras que permitían la recurrencia de ilicitudes. Sin embargo, se puso de manifiesto una vez más la ductilidad del Estado mexicano para manejar la temática mediante la creación de instituciones de atención como la CNDH. Dicha iniciativa, adoptada a principios de los años noventa, se explica entre otras razones por las tratativas para la aprobación del Tratado de Libre Comercio de Norte América (TlCAn o nAfTa, por su sigla en inglés), en el curso de las cuales se exhibía, entre otros reparos erigidos en Estados Unidos por los opositores al acuerdo, la problemática situación de los derechos humanos en México, en deuda con el sistema internacional de protección en la materia. De ahí que, paralelamente a las negociaciones para despejar el camino de la integración con Estados Unidos y Canadá, que incluyó la contratación de costosos especialistas en lobbying, se dieran internamente pasos para la creación de organismos públicos ad hoc, derivados del reconocimiento oficial de la necesidad de investigar abusos cometidos en el pasado reciente. Además, debía preverse el paulatino ajuste de la normatividad nacional y el entrenamiento de funcionarios y magistrados según la tratadística internacional sobre el tema suscrito por México ${ }^{15}$.

Este proceso continuaría en el marco de la transición a la democracia, mas no evitó que se presentaran actos represivos de excesiva violencia, como el de la masacre de Aguas Blancas, nuevamente en el estado de Guerrero, el 27 de noviembre de 1995, en la que por razones no muy claras murieron 17 indígenas y 21 resultaron heridos por los policías locales cuando estos detuvieron un camión en el que miembros de la Organización Campesina de

15 En ese contexto se ratifican varios tratados internacionales y se presenta el Programa Nacional de Promoción y Fortalecimiento de los DD. HH. (Bustillos, 2012, pp. 994-1004; Maza, 2008, pp. 39-42). 
la Sierra del Sur (ocss) se dirigían a un mitin político precisamente para reclamar por una desaparición ${ }^{16}$. El suceso produjo un impacto negativo en la imagen internacional del país, fijando la atención en los abusos cometidos por agentes del Estado contra la población rural y, en particular, contra las etnias originarias, con persistencia de una estructura de impunidad que contradice la voluntad expresa gubernamental de esclarecer ilícitos perpetrados por funcionarios del Estado (Sikkink, 1996, p. 157).

Al consagrarse la derrota en las elecciones nacionales de 2000 del hegemónico Partido Revolucionario Institucional (PRI), se esperaba el cumplimiento de la promesa de campaña electoral del nuevo presidente, perteneciente al antes opositor Partido Acción Nacional (PAN), Vicente Fox Quesada. Esta promesa estaba sustentada en la recomendación del informe de la CNDH de noviembre de 2001, respecto de la necesidad de investigar asuntos vinculados al pasado reciente sobre los que pudiera recaer responsabilidad estatal. Para ello, se creó una comisión especializada ${ }^{17}$, que fue la ya mencionada FEMospr. Pese al informe acusatorio que esta elaboró (primero el borrador que se filtró en 2006 y luego el oficial de 2007), no se libró de ser acusada de ciertas omisiones y, posteriormente, de que participaran en su gestión funcionarios presuntamente relacionados con los hechos investigados ${ }^{18}$.

La política que prometía corregir la impunidad al parecer fue orientada por un cálculo de costo-beneficio en el ámbito de alianzas entabladas por un gobierno que intentó, a partir del 2000,

\footnotetext{
16 Existe un video de los hechos: Matanza de Aguas Blancas. Puede consultarse en https://www.youtube.com/watch?v=Wut8XF07CM4

17 La recomendación (26/2001), asentada en el informe, dio cuenta de la necesidad de formar una estructura de investigación ad hoc debido a la responsabilidad del Estado por haber reaccionado autoritariamente ante un problema político, dando lugar a que "[...] Los derechos humanos de cientos de personas fueron desconocidos por grupos formados ex profeso en el ámbito de las fuerzas de seguridad por cuestión de agenda”. (CNDH, 2001).

18 En diferentes momentos se criticó, por ejemplo, el hecho de que Rafael Macedo de la Concha, titular de la PGR al momento de creación de la FEMOSPP, y encargado de designar al fiscal especial de la misma, fuese un militar que había colaborado con la Secretaría de Gobernación. Apoyado en (Academia, (2003). También se denunció a través de los medios que había funcionarios de la Fiscalía vinculados a la época represiva que se investigaba. Véase, por ejemplo, la acusación a Américo Meléndez, por su labor como agente del ministerio público en los años setenta, y en los noventa, al frente de la Policía Judicial de Nuevo León. (Aguayo y Treviño, (2005). Igualmente fue señalado José Sotelo Marbán, por su actuación previa en el estado de Chiapas. (Castillo, (2005).
} 
conciliar entre nuevo y antiguo régimen, configurando un cuadro inestable que determinó que las investigaciones y eventuales castigos de pasados delitos de lesa humanidad no se correspondieran con la aplicación estricta de los tratados internacionales firmados ni de las leyes promulgadas internamente ni de las sentencias logradas. Se concretó así un juego contradictorio para la institucionalidad democrática y la protección de derechos. A ello se sumó, ya entrado el siglo Xxi, la presencia abrumadora del crimen organizado y sus vínculos con las estructuras de seguridad y el sistema político en general, que arrojaría un saldo de más de 27000 personas presuntamente desaparecidas, según datos oficiales ${ }^{19}$, durante los últimos diez años, con expedientes que confirman una justicia ineficaz. Ello obliga a los agraviados, como ya se ha dicho, a recurrir a los organismos internacionales especializados ${ }^{20}$.

\section{El Estado sentenciado: el caso Rosendo Radilla}

Como corolario de lo expuesto, en noviembre de 2009 el Estado mexicano fue sentenciado por primera vez en un caso de desaparición forzada durante la "guerra sucia", por parte de la COIDH. Rosendo Radilla, cuya situación originó esta resolución, desapareció en el estado de Guerrero el 25 de agosto de 1974. En la sentencia, representativa por hacer pública internacionalmente la represión política de los años de "guerra sucia" en un estado que acumuló el mayor número de desapariciones y cuatro décadas después continúa sufriéndolas, se sostiene, entre otros puntos, "por unanimidad y en lo sustantivo, que el Estado mexicano: [...] es responsable de la violación de los derechos a la libertad personal, a la integridad personal, al reconocimiento de la personalidad jurídica y a la vida”. Se señala también que “debe conducir

19 El gobierno federal tiene un registro total de 27 mil 659 desaparecidos, desde 2007 hasta el 31 de diciembre de 2015. El Registro Nacional de Datos de Personas Extraviadas o Desaparecidas (RNPED) da cuenta que, de todos los casos, 989 están relacionados con el fuero federal y 26 mil 670 con el fuero común". (Vicenteño, 2016). 20 En 2015 se presentaron 1164 peticiones a la CIDH, provenientes de los 35 estados miembros, "de éstas, 849 fueron contra el gobierno mexicano, es decir, 73 por ciento del total”. (Juárez, 2016, p. 9). 
eficazmente, con la debida diligencia y dentro de un plazo razonable la investigación y, en su caso, los procesos penales que tramiten en relación con la detención y posterior desaparición forzada”. Igualmente, México queda obligado a "continuar con la búsqueda efectiva y la localización inmediata del señor Rosendo Radilla Pacheco o, en su caso, de sus restos mortales" (COIdH, 2009). Se indica que en el periodo en que ocurrieron los hechos aludidos también se presentaron numerosos casos similares en otras partes del territorio mexicano, cuyo acervo probatorio consta en la CNDH. Y efectivamente, la situación de Radilla es ejemplo de la de otros cientos de víctimas ignoradas por su marginalidad social en la región sureña de Guerrero y en particular en el pueblo de Atoyac de Álvarez. El año de su desaparición fue quizá el más virulento en cuanto a represión gubernamental en esa zona: en esta época, la guerrilla encabezada por el maestro rural y líder campesino Lucio Cabañas mantenía secuestrado al senador y gobernador electo del estado, Rubén Figueroa. El ejército mexicano lanzó entonces una campaña contra dicho movimiento que afectó también a la población civil de la zona. Se buscaba información sobre el secuestro y también aislar a la guerrilla. En la detención y posterior desaparición de Rosendo Radilla es evidente que la motivación fue su manifiesta simpatía hacia el movimiento armado, que expresaba en sus canciones o corridos, dato registrado en la sentencia de la COIDH de 2009 y en los estudios al respecto citados en estas páginas.

Para las organizaciones de DD. HH. en México, el caso de Radilla se ha constituido en un símbolo de la poco conocida represión política de los años sesenta y ochenta del siglo pasado, al ser la primera demanda con esas características que accedió a la COIDH y dio lugar a sentencia luego de un inútil y largo peregrinar por instancias de procuración de justicia del país. Transcurridos muchos años y habiendo sido regularmente desestimada la denuncia, enviada a reserva en virtud de que no existían datos probatorios de responsabilidad alguna, y ante una evidente falta de voluntad oficial para generar una instrumentación efectiva de la investigación, se presentó el expediente en 2001 ante la CIDH (CMDPdH, 2008). Esta lo elevó a la CoIDH, de donde devino la sentencia de 2009.

La conclusión era que pese a la señal de cambio en el ámbito de los organismos nacionales de protección de los derechos 
humanos, existían -y existen- fuertes obstáculos para visibilizar los hechos de la represión, sus efectos delictivos y, más aún, para señalar responsables ${ }^{21}$. El caso Radilla muestra algunos de los impedimentos que la procuración de justicia mexicana interpuso, como por ejemplo la prerrogativa del fuero militar para los acusados pertenecientes a las fuerzas armadas. La sentencia interamericana finalmente obligó a remover ese obstáculo el 11 de julio de 2014. Sin embargo, el reconocimiento a la Suprema Corte de Justicia de la Nación (scJN) de México otorgado por la onu en 2013 en virtud del avance efectuado en la instrumentación jurídica de la defensa de los derechos humanos, como se apuntó anteriormente, propició una imagen internacional que no se ajusta a la persistencia de prácticas violatorias. Aunque algunas de las indicaciones de la sentencia fueron atendidas en distintos grados, los esfuerzos por aclarar las circunstancias de la desaparición y lograr localizar los restos de la víctima no han sido satisfactorios. El Estado, tanto el ejecutivo como su dependencia encargada, la Procuraduría General de la República (en adelante PGR), no asumieron la responsabilidad de actuar imparcialmente involucrando a grupos independientes que participaran en la investigación y búsqueda del detenido desaparecido.

Se aprecia desde entonces un trabajo muy lento, sin ubicación de los informantes claves: los participantes en la detención y posterior desaparición forzada de la víctima. Algunos responsables de las diligencias (encargados de las excavaciones relacionadas) coinciden en la limitación que impone la ausencia de información proveniente del sector militar ${ }^{22}$, lo que supone implícitamente un respaldo gubernamental a dicha omisión (Dutrénit y Jaloma 2014; Dutrénit, 2014).

21 En el Informe Final de la FEMOSPP se puede apreciar la advertencia sobre la obligación de investigar: "Los principales hechos que consideramos deben de ser esclarecidos, en respuesta a las demandas de la sociedad, es lo sucedido en torno al movimiento estudiantil de 1968 y las políticas de Estado que ocasionaron la represión del movimiento estudiantil, la suerte de los detenidos que fueron desaparecidos durante la llamada 'guerra sucia', el trato que recibieron los detenidos que fueron señalados de apoyar la guerrilla y las políticas de contrainsurgencia que siguió el Estado mexicano llegando, incluso, a la ejecución extrajudicial de los detenidos, así como los delitos de lesa humanidad que instrumentó en contra de su propia población”. 22 Distintos entrevistados por Silvia Dutrénit (activistas de derechos humanos, litigantes ante la CIDH para el caso Radilla y antropólogos forenses participantes en las diligencias en Atoyac de Álvarez) coinciden en esa ausencia de información castrense. Recientemente se anunció que militares involucrados en el caso Ayotzinapa declararían ante el ministerio público, lo que ha sido recibido con desconfianza por familiares de las víctimas, que temen sea solo una puesta en escena (Román, 2016, p. 13). 


\section{El Estado impugnado: Ayotzinapa en el mundo}

Viejas prácticas de inoperancia en la procuración de justicia mexicana, presunción de colusión de algunos sectores políticos y de las corporaciones de seguridad con delitos pendientes de atención, se suman a la convicción de que actualmente también existen complicidades con los incesantes atropellos del crimen organizado. No es de extrañar que también desde la sociedad civil los sectores vulnerados al verse enfrentados a la irresolución de sus demandas busquen apoyo en el SIDH.

Lo sucedido a partir del 26 de septiembre de 2014 a los estudiantes de Ayotzinapa ratificó una vez más la inoperancia oficial, que no supo dar respuesta inmediata a los hechos de violencia pública y notoria en la ciudad de Iguala (otra vez en Guerrero) en los que se vieron envueltos directa o indirectamente distintos órdenes de la estructura política y de las corporaciones de seguridad municipal, estatal y federal. El mundo entero en tiempo real tomó conocimientos de los hechos consistentes en la desaparición de 43 educandos de la Escuela Normal Rural "Raúl Isidro Burgos", así como la tortura hasta la muerte de otro más y el asesinato de algunas personas ajenas por completo a los hechos, pero presentes en el lugar.

Las investigaciones producidas han generado distintas explicaciones, en particular una oficial ${ }^{23}$ que apenas ha cambiado luego de lo declarado en los días subsiguientes, cristalizada en la llamada "verdad histórica" reconstruida por las instancias de gobierno, según expresión del Procurador General de la República de entonces, Jesús Murillo Karam ${ }^{24}$, intentando así cerrar el caso. Versión ratificada en abril de 2016, al darse a conocer el tercer y controvertido peritaje del basurero de Cocula, donde se afirmaba que se habrían incinerado los cadáveres ${ }^{25}$. Una vez más, las

\footnotetext{
23 "La noche del 26 de septiembre policías de Iguala y Cocula, obedeciendo órdenes del alcalde igualteco, atacaron a los normalistas de Ayotzinapa, mataron a tres y a otros 43 se los entregaron a Guerreros Unidos, grupo que presuntamente los asesinó e incineró” (Hernández y Fisher, 2014). 24 Murillo Karam afirmó que los estudiantes normalistas fueron "privados de la libertad, privados de la vida, incinerados y arrojados al río. En ese orden. Esta es la verdad histórica de los hechos, que debe tener validez jurídica en ese orden ante los órdenes jurisdiccionales" (Milenio, 2015).

25 Murillo Karanm ratifica su verdad histórica y es criticado y relativizado por los expertos y científicos internacionales. Apoyado en (García, (2016).
} 
autoridades se vieron atrapadas en la complejidad de su ambivalente juego político: al tiempo que se expresaba preocupación, voluntad y dedicación para establecer los hechos en cuestión, se hacía un discurso y una presentación engañosos de los hechos y posibles evidencias. Se incrementaba con ello la victimización de los familiares y se fomentaba a nivel nacional e internacional el descrédito (Beristain, 2017; Hernández, 2016, pp. 71-236 y 317-354).

Algunas de las recomendaciones que Amnistía Internacional (en adelante AI) realizó en octubre de 2014 señalan esta brecha entre discurso y acción: “3) Enrique Peña Nieto debe acelerar y garantizar una investigación rápida y exhaustiva sobre estos terribles abusos, y que se llegue a fondo sobre lo ocurrido a las víctimas. Las promesas de México acerca del respeto a los derechos humanos no deben quedar en meras declaraciones que permitan una serie de abusos con total impunidad. 4) Se debe garantizar el acceso pleno a las investigaciones ministeriales por parte de los familiares de las víctimas y sus representantes, y asegurar que no recaiga en las víctimas y sus familiares la obligación de obtener y proporcionar los elementos de prueba” (Amnistía Internacional, 2014).

Lo dicho por AI se basaba en una contradicción revelada por el trabajo de dos organismos independientes coadyuvantes: el Equipo Argentino de Antropología Forense (en adelante EAAF), reconocido por su labor en tareas similares desempeñadas en Argentina y en varios países, y el GIEI, formado por acuerdo entre el gobierno mexicano y la CIDH. La infructuosa búsqueda de los estudiantes, el hallazgo de los restos de uno de ellos en condiciones de dudosa ubicación que desembocó en una relación tirante con el EAAF, los crecientes reclamos de verdad y justicia y la crítica a las condiciones de parcialidad que regían la investigación, orillaron al gobierno mexicano a acordar con la CIDH. Ello posibilitó al GIEI trabajar en México durante un año aunque con ciertos candados que trabaron aspectos de la investigación, según se advierte a partir de declaraciones de sus integrantes (Beristain, Valencia, Buitrago y Cox, 2017, pp. 205-248).

En tanto, el 23 de julio de 2015 la CNDH dio a conocer 32 puntos conteniendo observaciones y solicitudes a la autoridad mexicana, apuntando a serias deficiencias en la encuesta, así fueran de carácter metodológico o científico. La Fiscalía ni siquiera contaba 
con una ficha de identidad para cada una de las 43 víctimas, dato esencial para la investigación (FORBEs, 2016). Posteriormente, la CNDH también exhortó a abrir otras rutas:

La información que se da a conocer constituye, de facto, el punto de partida de una segunda "Ruta de Desaparición”, que deberá ser investigada por la autoridad competente para determinar con certeza lo sucedido [...] una vez que agentes policiales los sustrajeron del lugar antes referido [...]. Este fenómeno de posible cooptación de elementos de instituciones policiales por parte de organizaciones delictivas habría quedado evidenciado en los municipios de Iguala y Cocula, con la presunta participación de agentes de Policía pertenecientes a dichos municipios en los actos de desaparición de los estudiantes de la Escuela Normal "Raúl Isidro Burgos" de Ayotzinapa, la noche del 26 al 27 de septiembre de 2014. Hoy damos a conocer información que haría presumir la participación de elementos de la Policía Municipal de Huitzuco y de dos elementos de la Policía Federal en los hechos ocurridos en el denominado "Puente del Chipote" de Iguala. (CNDH, 2016) ${ }^{26}$

Todo apuntaba a que existen muchos entretelones en la investigación, así como pistas no atendidas. ${ }^{27}$ Un poco antes, en febrero de 2016, el EAAF había dado también a conocer su dictamen, indicando que en la investigación multidisciplinaria realizada, la evidencia biológica y no biológica recolectada durante los peritajes no respalda la hipótesis de la PGR acerca de la "verdad histórica" (EAAF, 2016). No era concebible, de acuerdo a los indicios, que en el lugar señalado (el basurero municipal de Cocula) se hubiera generado en esas fechas un fuego de tal magnitud que posibilitara incinerar a 43 cadáveres. Tampoco existían suficientes pruebas científicas para relacionar presuntos restos de los estudiantes con

26 Palabras del licenciado Luis Raúl González Pérez, presidente de la CNDH, y del maestro José T. Larrieta Carrasco, titular de la Oficina Especial del caso Iguala, al dar a conocer el reporte sobre la posible participación de elementos de la policía municipal de Huitzuco y de dos agentes de la policía federal en la desaparición de los normalistas que viajaban en el autobús 1531, ocurrida en el 'puente del Chipote' de Iguala, el 26 de septiembre de 2014 (CNDH, 2016).

27 Un análisis detallado se encuentra en las publicaciones de Hernández (2016) y Beristain et ál. (2017). 
muestras analizadas recolectadas en el mismo lugar, ni se tenían elementos suficientes para vincular en forma directa los restos hallados en el basurero con los recuperados, según la PGR, en el río San Juan, donde se "encontró" la única muestra de identificación positiva perteneciente al estudiante Alexander Mora Venancio, integrante del grupo de los desaparecidos. ${ }^{28}$

Por su lado, el GIEI desde su primer informe, indicaba posibles pistas y la necesidad de que se realizaran peritajes conjuntos de la PGR con el EAAF, así como obligatoriedad de nuevos testimonios que incluyeran a militares y otras diligencias tendientes a develar distintas cuestiones relacionadas. Tales recomendaciones no fueron satisfechas y esta cooperación internacional en el ámbito de protección de los derechos humanos acabó siendo criticada, y una campaña de desacreditación dirigida recayó sobre los cooperantes extranjeros, especialmente los del GIEI y por extensión sobre la CIDH y su secretario ejecutivo, sacando a relucir fobias contra la injerencia de "lo extranjero" con el objeto de descalificar su tarea. Inevitablemente, las sospechas sobre el origen de estos infundios se orientaron al ámbito gubernamental (Sin Embargo, 2015; Ayuso, 2016; Beristain et ál., 2017).

Los dictámenes de ambos grupos de expertos son contradictorios con lo expuesto por las autoridades. En distintos momentos, los informes del EAAF y del GIEI dan cuenta documentada de sucesos que impugnan las versiones oficiales, que como es obvio, se elaboraron mediante procedimientos seleccionados y ejercidos por actores no independientes (GIEI, 2015, 2016), cuestión fundamental para una investigación como la que se tiene entre manos, así como la que aún se mantiene para el caso Radilla. En este contexto, la directora para las Américas de AI señaló que "la determinación absoluta del gobierno mexicano de esconder la tragedia de Ayotzinapa debajo de la alfombra parece no tener límites"; y el informe respectivo indica que:

28 En su dictamen de febrero de 2016 pone énfasis en serias irregularidades producto de la recolección de evidencia en el basurero de Cocula por peritos de la PGR y de Ministerios Públicos el 15 de noviembre de 2014 sin dar aviso al EAAF. Ambos debían trabajar en conjunto en todas las diligencias periciales de búsqueda por disposición del entonces procurador Murillo Karam en acuerdo con los familiares de los estudiantes (EAAF, 2016a). 
Al negarse a dar seguimiento a todas las posibles líneas de investigación, manipular evidencia, no proteger ni apoyar a las familias de los estudiantes, negar el pedido de extender el mandato del GIEI y no haber estado en la presentación [del informe], las autoridades mexicanas están enviando el peligroso mensaje que cualquiera puede desaparecer en México sin que se haga nada al respecto. (Amnistía Internacional, 2016)

El acompañamiento internacional que se mantiene casi tres años después de la desaparición de los estudiantes de Ayotzinapa ha sido clave para mantener la presión y vigilancia sobre el caso, junto a la sostenida demanda de los familiares. No ha sido, empero, suficiente para el esclarecimiento. ${ }^{29}$

Una vez entregados los informes del EAAF y del GIEI, la CIDH estableció en 2016 un mecanismo para dar seguimiento "a las medidas cautelares o de protección dictadas por la CIDH en octubre de 2014 y a las recomendaciones formuladas en los informes del Grupo Interdisciplinario de Expertos Independientes (GIEI)". ${ }^{30}$ Ningún avance significativo se ha dado hasta el presente y como sostuvo la CIDH en 2014, “a pesar de los informes emitidos por el GIEI y las recomendaciones respectivas, las acciones adoptadas por las autoridades estatales aún no han arrojado resultados concretos o avances positivos" (DW, 2016).

A fines de agosto de 2017 se llevó a cabo la tercera visita de los comisionados de la misma CIDH como parte del mecanismo de seguimiento. Con la presencia de secretarios de Estado, funcionarios de la PGR y algunos familiares de los normalistas desaparecidos, la delegación exigió al gobierno mexicano no descartar la línea de investigación de un quinto autobús que ya había sido presentada en el informe de 2015: "Se plantea como teoría de caso la existencia del quinto autobús y la posibilidad de que estuviera cargado de heroína

\footnotetext{
29 El 26 de octubre de 2017 se realizó en Montevideo la última audiencia de la CIDH sobre el caso Ayotzinapa. El hecho refuerza la percepción del acompañamiento internacional que mantienen los sucesosla desaparición de los 43 normalistas. 30 El presidente de la CIDH, James Cavallaro, señaló que durante una visita a México, “...los integrantes de la Comisión se quedaron impresionados por los niveles de violencia e impunidad que imperan en amplias regiones de México y no solamente en el estado Guerrero, que registra una de las tasas más altas de homicidios en el país y donde desaparecieron los estudiantes de magisterio... [...]. 'Es como si no hubiera interés en buscar a los responsables y esclarecer los crímenes'”.
} 
o de dinero, que los jóvenes tomaron sin saberlo entre el resto de los autobuses, y que eso explicaría el ataque masivo llevado a cabo contra ellos" (Beristain et ál., 2017, p. 255).

Esto vincularía el tráfico de drogas con la desaparición de los normalistas. Asimismo, se reclamó la aprobación de la Ley General contra la Desaparición Forzada, cuya tardanza fue notoriamente significativa en relación con los más de 27000 desaparecidos y personas no localizables en el territorio. ${ }^{31} \mathrm{Su}$ promulgación se efectuó el 16 de noviembre de 2017 con el nombre de Ley de desaparición forzada de personas, desaparición cometida por particulares y creación del Sistema Nacional de Búsqueda de Personas. Frente a los reclamos del organismo internacional y los familiares, el gobierno busca afirmar su "compromiso" con un tema neurálgico: la búsqueda de los desaparecidos. ${ }^{32}$ Pero hay que entender que la ley es solo un instrumento y falta mucho para una implementación que cumpla con la demanda de familiares y organismos internacionales.

\section{Conclusión}

Como se ha dicho, durante el periodo de la guerra fría el Estado mexicano tuvo diferentes estrategias para relacionarse con la izquierda. Perseguidos de los autoritarismos y dictaduras en otros países de América Latina encontraron refugio en México, al tiempo que el gobierno reprimía a la oposición armada interna con métodos que investigaciones oficiales posteriores reconocieron como delitos de Estado. Sin embargo, durante mucho tiempo una

31 No obstante esa cifra, en junio de 2017 distintas fuentes retomaban otra de la Secretaría de Gobernación (SEGOB). "Es la primera vez que se rebasa el número de 32 mil casos, tanto del fuero común (casi 97 por ciento del total) como del federal, de acuerdo con el corte estadístico más reciente, del 30 de abril pasado', ha informado hoy viernes el diario mexicano La Jornada, citando las últimas estimaciones de la Secretaría de Gobernación de México (SEGOB). El diario señala que en enero de 2017 la suma nacional fue de 30942 personas no localizadas o desaparecidas, lo que supone 1276 casos adicionales en un trimestre" (HIIISPANTV Nexo latino, 2017).

32 Se trató de una ceremonia cerrada en la que el presidente Peña Nieto señalo que "La Ley General sobre Desapariciones Forzadas y Desapariciones por particulares [se trata de un] nuevo marco legal [que] pone fin a décadas en que no se había querido reconocer un problema que ataca a la sociedad, establece una base sólida para sistematizar un esquema de búsqueda de desaparecidos y pugna por hacer justicia a las víctimas de desapariciones forzadas" (Urrutia y Martínez, 2017). 
alta proporción de estos ilícitos y sus correspondientes víctimas se mantuvieron invisibles, especialmente en el medio rural. Fue por repercusión de la sentencia sobre el caso Radilla que tomaron estado público las desapariciones políticas del pasado al ocuparse del tema la Organización de Naciones Unidas, aunque también de manera previa el sIDH. Luego, al presentarse el caso de Aytozinapa, el Estado mexicano volvió al banquillo de los acusados al ponerse en evidencia su débil institucionalidad en la defensa y promoción de los Derechos Humanos, pese a que anteriormente se habían creado instancias internas para ello, considerando también la desaparición por efectos multifactoriales a partir del nuevo milenio.

En términos prácticos, y tomando especialmente en cuenta el trabajo que llevó a cabo el GIEI en torno a Ayotzinapa bajo la órbita de la CIDH, ¿qué resultados y recomendaciones deja, aun cuando no se haya renovado dicho acuerdo de cooperación, contrariando el deseo de las víctimas y las declaraciones de actores internacionales sobre la grave situación de derechos humanos en México?33.

La actuación de un grupo independiente con experiencia profesional multidisciplinaria deja una lección en cuanto a la importancia de atender a las víctimas y curar las fallas de un sistema que, por razones estructurales, poco responde a su cometido. También aporta elementos de búsqueda por medio de nuevos indicios encontrados y pone énfasis en la necesidad de que el cuerpo de peritos sea independiente del Estado y combine diversas disciplinas para detectar la tergiversación de pruebas. Hace recomendable construir un sistema de justicia penal con capacidad de investigar graves violaciones de los derechos humanos en vez de producir nuevos agravios contra los afectados -y aun contra "falsos positivos"-. Exhorta, en suma, a evitar la revictimización y la criminalización, y a sostener una actitud positiva respecto de la cooperación internacional.

33 También el gobierno de Estados Unidos ha dado su respaldo a la labor del GIEI y recomendado al gobierno mexicano tomar en cuenta sus observaciones. El caso Ayotzinapa, para Estados Unidos, resulta no menos embarazoso en función de su estrecha relación con México, criticada por razones humanitarias o económicas por opositores de aquel país (Ayuso, 2016b). 


\section{Referencias}

Academia Mexicana de Derechos Humanos, Acción de los Cristianos por la Abolición de la Tortura, Asociación de Familiares de Detenidos Desaparecidos y Víctimas de Violaciones a Derechos Humanos en México, Asociación Mexicana para el Derecho a la Información, Asociación Mundial de Radios Comunitarias- México, Centro de Derechos Humanos "Fray Francisco de Vitoria OP” AC Centro de Derechos Humanos "Miguel Agustín Pro Juárez", Centro Nacional de Comunicación Social, Centro por la Justicia y el Derecho Internacional, Comisión Mexicana de Defensa y Promoción de los Derechos Humanos, AC, Foro Migraciones Franciscans International - Sección México Fundación Diego Lucero Liga Mexicana de Defensa de los Derechos Humanos, Red Nacional de Organismos Civiles de Derechos Humanos "Todos los derechos para todos" Servicios y Asesoría para la Paz (febrero de 2003). La impunidad en México. Informe que presentan organizaciones mexicanas a la Comisión interamericana de derechos Humanos. Recuperado de http://biblioteca. cejamericas.org/bitstream/handle/2015/574/impunidad-mexico. pdf? sequence $=1$ \&isAllowed $=y$

Aguayo Quezada, S., y Treviño, J. (13 de noviembre de 2005). Ni verdad ni justicia. Proceso, 1515, 50-56.

Amnistía Internacional (24 de abril de 2016). México: Nuevo informe sobre desapariciones de Ayotzinapa revela la determinación gubernamental para esconder esta tragedia. Recuperado de https://www.amnesty. org/es/press-releases/2016/04/mexico-new-report-on-ayotzinapadisappearances-reveals-governments-determination-to-sweep-tragedyunder-the-carpet/

Amnistía Internacional (9 de octubre de 2014). Recomendaciones de Amnistía Internacional sobre el caso Ayotzinapa. Recuperado de http:// www.tlachinollan.org/comunicado-recomendaciones-de-amnistiainternacional-sobre-el-caso-ayotzinapa/http://www.tlachinollan. org/comunicado-recomendaciones-de-amnistia-internacionalsobre-el-caso-ayotzinapa/http://www.tlachinollan.org/comunicadorecomendaciones-de-amnistia-internacional-sobre-el-caso-ayotzinapa/ http://www.tlachinollan.org/comunicado-recomendaciones-deamnistia-internacional-sobre-el-caso-ayotzinapa/

Astorga, L. (2007). Seguridad, traficantes y militares. (El poder y la sombra.) Tiempo de Memoria. México: Tusquets.

Ayuso, S. (8 de abril de 2016a). México niega estar tras los ataques a la CIDH y los expertos de Ayotzinapa. En El País. Recuperado de http://internacional.elpais.com/internacional/2016/04/07/ mexico/1460065047_518868.html. 
Ayuso, S. (25 de abril de 2016b). EE. UU. pide a México que estudie cuidadosamente las recomendaciones de los expertos de Iguala. En El País. Recuperado de http://internacional.elpais.com/ internacional/2016/04/25/estados_unidos/1461619661_995728.html.

Beristain, C. M. (2017). El tiempo de Ayotzinapa. España-México: FOCA.

Beristain, C. M., Valencia, A., Buitrago, A., y cox, F. (2017), Metodologías de investigación, búsqueda y atención a las víctimas. Del caso Ayotzinapa a nuevos mecanismos en la lucha contra la impunidad. Bogotá: TemisFLACSO/México.

Brooks, D. (24 de mayo de 2016). Crisis financiera en la CIDH; alerta sobre recorte de personal. La Jornada, p. 19.

Bustillos, J. (2012). Caso Radilla. Paradigma de la protección constitucional de los derechos humanos frente a la responsabilidad del estado mexicano. Boletín Mexicano de Derecho Comparado, 135, 989-1022.

Carr, B. (1996). La izquierda mexicana a través del siglo XX. México: Era. Castellanos, L. (2008). México Armado. 1943-1981. México: Era.

Castillo García, G. (27 de febrero de 2005). Continúa en la FEMospP funcionario señalado como genocida por la cIDH. La Jornada. Recuperado de http://www.jornada.unam.mx/2005/02/27/index. php?section $=$ politica \& article $=015 \mathrm{n} 1 \mathrm{pol}$

Centro de Derechos Humanos Miguel Agustín Pro Juárez, Fundar, H.I.J.O.S., Comisión Mexicana de Defensa y Promoción de los Derechos Humanos, Fundación Diego Lucero, Asociación de Familiares de Detenidos Desaparecidos y Víctimas de Violaciones a los Derechos Humanos en México, Comité 68, Unión de Madres con Hijos Desaparecidos de Sinaloa, Comité de Madres de Desaparecidos Políticos de Chihuahua, Nacidos en la Tempestad, Red Nacional de Organismos Civiles de Derechos Humanos "Todos los Derechos para Todas y Todos" (2014). Desapariciones forzadas durante la guerra sucia en México e impunidad. Recuperado de http://fundar.org.mx/wp-content/ uploads/2015/01/Prodh-et-al.pdf.

Centro de Noticias ONU (13 de febrero de 2015). México: ONU llama a autoridades a cumplir Convención sobre Desapariciones Forzadas. Recuperado de http://www.un.org/spanish/News/story. asp?NewsID=31661\#.V0ReuteWSUc.

CMDPDH (2008). La desaparición forzada de Rosendo Radilla en Atoyac de Álvarez. Informe de afectación psicosocial. México: CMDPDH.

CNDH (14 de abril de 2016). Palabras del Lic. Luis Raúl González Pérez. Recuperado de http://www.cndh.org.mx/palabras.

CNDH (2001). Informe Especial sobre las quejas en materia de desapariciones forzadas ocurridas en la década de los 70 y principios de los 80 . Recuperado de http://www.cndh.org.mx/sites/all/doc/Informes/Especiales/2001_ Desapariciones70y80.pdf. 
CNN (2013). El caso Radilla es declarado patrimonio mundial por la UNESCO. Últimas noticias, blog de CNN México. Recuperado de http://blogs.cnnmexico.com/ultimas-noticias/2013/11/10/el-casorosendo-radilla-es-declarado-patrimonio-mundial-por-la-unesco/.

COIDH. Caso Bámaca-Velásquez Vs. Guatemala. Fondo. Sentencia de 25 de noviembre de 2000. Serie C No. 70. Recuperado de http://www. corteidh.or.cr/docs/casos/articulos/Seriec_91_esp.pdf.

COIDH. Caso Radilla Pacheco Vs. Estados Unidos Mexicanos. (Caso 12.511). Sentencia 23 de noviembre, 2009. Recuperado de http://www. corteidh.or.cr/docs/casos/articulos/seriec_209_esp.pdf.

Dutrénit, S. (2014). Rosendo Radilla Vs. The Mexican Government: Visibility and Invisibility in a Crime and its Reparation. Asian Journal of Latin American Studies, 27(3), 73-100. Recuperado de http://www.ajlas. org/v2006/paper/2014vol27no304.pdf.

Dutrénit, S. (2011). La embajada indoblegable. Asilo mexicano en Montevideo durante la dictadura. Montevideo: Editorial Fin de Siglo-ICP/UdelaR.

Dutrénit, S., y Jaloma, E. (2014). Recuerdos y relatos sobre la búsqueda de un detenido desaparecido en México. Estudios. Centro de Estudios Avanzados-UNC, 31, 181-202.

Dutrénit, S., y Varela, G. (2010). Tramitando el pasado. Violaciones de los derechos humanos y agendas gubernamentales en casos latinoamericanos. México: CLACSO/FLACSO.

$D W$ (30 de julio de 2016).CIDH anuncia términos de mecanismo de seguimiento del caso Ayotzinapa. Recuperado de http://www.dw.com/ es/cidh-anuncia-t\%C3\%A9rminos-de-mecanismo-de-seguimiento-delcaso-ayotzinapa/a-19438496

EAAF (febrero de 2016a). Dictamen sobre el Basurero de Cocula. Recuperado de http://www.eaaf.org/files/dictamen-sobre-el-basurero-coculafeb2016-2.pdf.

EAAF (8 de febrero de 2016b). Resumen ejecutivo. Recuperado de http:// aristeguinoticias.com/1002/mexico/el-dictamen-de-los-peritosargentinos-sobre-el-basurero-de-cocula-documento/

Economíahoy.mx (23 de marzo de 2016). CIDH resalta que México sigue fallando en resolver su "grave" crisis de derechos humanos.

Recuperado de http://www.economiahoy.mx/internacional-eAmmexico/noticias/7392380/07/17/CIDH-pide-a-Mexico-que-reconozcagravedad-de-su-crisis-en-derechos-humanos.html

FEMOSPP (26 de febrero de 2006). Borrador del Informe del Fiscal Especial. Recuperado de https://nsarchive2.gwu.edu//NSAEBB/NSAEBB180/ index2.htm

Flores, L. (24 de noviembre de 2014). Del 'Momento mexicano' a la tragedia. En Sinembargo.com. Recuperado de http://www.sinembargo. $\mathrm{mx} / 24-11-2014 / 1175428$. 
Forbes (23 de julio de 2015). CNDH detecta "serias fallas" en investigación del caso Ayotzinapa. Recuperado de http://www.forbes.com.mx/cndhdetecta-serias-fallas-en-investigacion-del-caso-ayotzinapa/

García, D. A. (2 de abril de 2016). Tercer peritaje en Cocula no es concluyente: forenses argentinos. En El Universal. Recuperado de http://www.eluniversal.com.mx/articulo/nacion/ seguridad/2016/04/2/tercer-peritaje-en-cocula-no-es-concluyenteforenses-argentinos

GIEI (2016). Ayotzinapa II. Avances y nuevas conclusiones sobre la investigación, búsqueda y atención a las víctimas. Recuperado de http:// hilodirecto. com.mx/informe-final-del-giei-sobre-ayotzinapa-documento-en-pdf/

GIEI (septiembre de 2015). Informe Ayotzinapa. Investigación y primeras conclusiones de las desapariciones y homicidios de los normalistas de Ayotzinapa. Recuperado de http://redtdt.org.mx/wp-content/ uploads/2015/09/Informe-ayotzi.pdf

Gómez, N. (26 de marzo de 2016). Niegan visita a relator de tortura de la ONU. En El Universal. Recuperado de http://www.eluniversal.com. $\mathrm{mx} /$ articulo/nacion/politica/2016/03/26/niegan-visita-relator-detortura-de-la-onu.

Hernández, A. (2016). La verdadera noche de Iguala. La historia que el gobierno trató de ocultar. México: Grijalbo.

Hernández, A., y Fisher, S. (13 de diciembre de 2014). Iguala: la historia no oficial. Proceso, 2145. Recuperado de: http://hemeroteca.proceso.com. $\mathrm{mx} /$ ?page_id=278958\&a51dc26366d99bb5fa29 cea4747565fec $=390593$

HIIISPANTV Nexo Latino (2 de junio de 2017). Segob: Número de desaparecidos en México supera 32.000. Recuperado de http://www. hispantv.com/noticias/mexico/343288/crece-numero-desaparecidossegob-violencia

Juárez, B. (29 de mayo de 2016). Contra el Estado mexicano, 73\% de las denuncias ante la CiDH: Álvarez Icaza. En La Jornada, p. 9.

Le Clerecq, J. A. y Rodríguez Sánchez Lara, G. (Coords.) (2016). Índice global de impunidad México 2016 (IGI-MEX). México: UDLAPConsejo Ciudadano-CESIJ/UDLAP.

López Macedonio, M. N. (2010). Historia de una colaboración anticomunista transnacional. Los tecos de la Universidad Autónoma de Guadalajara y el Gobierno de Chiang Kai-Shek a principios de los años setenta. Contemporánea. Historia y problemas del siglo XX, 1, 133158. Recuperado de http://www.geipar.udelar.edu.uy/wp-content/ uploads/2012/05/09_Dossier07.pdf

Martínez Corbalá, G. (1998). Instantes de decisión. Chile 1972-1973. México: Grijalbo.

Matanza de Aguas Blancas (1995). Matanza de Aguas Blancas. Recuperado de https://www.youtube.com/watch?v=Wut8XF07CM4 
Maza, E. (2008). Los derechos humanos en México: ¿retórica o compromiso? México: FLACSO.

Moreno González, M. G. (2017). El movimiento anticomunista en Jalisco durante los años setenta. Espiral, XXIV(68). Recuperado de http:// www.redalyc.org/articulo.oa?id=13848276004

Milenio Digital (27 de enero de 2015). Asesinados, incinerados y arrojados al río, verdad histórica: PGR. Recuperado de http://www. milenio.com/policia/Asesinados-incinerados-arrojados-historicaPGR_0_453554859.html

Montemayor, C. (2010). La violencia de Estado en México. Antes y después de 1968. México: Debate.

National Security Archive (2006). Official Report Released on Mexico's "Dirty War". Government Acknowledges Responsibility for Massacres, Torture, Disappearances and Genocide. Recuperado de http://nsarchive.gwu.edu/ NSAEBB/NSAEBB209/.

Notimex (5 de diciembre de 2013).SCJN obtiene el Premio de Derechos Humanos de la ONU. En El Financiero. Recuperado de http://www. elfinanciero.com.mx/archivo/scjn-obtiene-el-premio-de-derechoshumanos-de-la-onu.html.

Oficina del Alto Comisionado de las Naciones Unidas para los Derechos Humanos (2009). Desapariciones forzadas o involuntarias. Folleto informativo, 6/rev.3. Recuperado de http://www.ohchr.org/ Documents/Publications/FactSheet6Rev3_sp.pdf

Oficina del Alto Comisionado de las Naciones Unidas para los Derechos Humanos. (2006). Convención Internacional para la protección de todas las personas contra las desapariciones forzadas. Recuperado de http://www.ohchr.org/SP/ProfessionalInterest/Pages/ ConventionCED.aspx.

ONU (2014). Informe de Juan Méndez, relator especial sobre la tortura y otros tratos o penas crueles, inhumanos o degradantes, para México. Recuperado de http://www.hchr.org.mx/images/doc_pub/G1425291.pdf

Ramírez, J. (1 de julio de 2005). Revive un ex guerrillero su detención y tortura durante la guerra sucia. La Jornada. Recuperado de http://www.jornada.unam.mx/2005/07/01/index. php?section $=$ politica\& article $=022 \mathrm{n} 1 \mathrm{pol}$

Rangel Lozano, C. (2012). La recuperación de la memoria mediante testimonios orales. La desaparición forzada de personas en Atoyac, Guerrero. En A. Radilla Martínez, y C. Rangel Lozano (coords.), Desaparición forzada y terrorismo de Estado en México. Memorias de la represión en Atoyac, Guerrero, durante la década de los setenta. México: Plaza y Valdés-UAG. pp. 136-85.

Rodríguez Tovar, J. C. (6 de abril de 2002). La ultraderecha mexicana en la Operación Cóndor. Reunión en Guadalajara en 1974. Proceso, 2145. Recuperado de http://www.proceso.com.mx/187331/la-ultraderechamexicana-en-la-operación condor 
Román, J. A. (25 de mayo de 2016). Respuesta de soldados a cuestionario del GIEI no serán creíbles: padres de los 43. En La Jornada, p. 13.

Sánchez Serrano, E., Ferrer Vicario, G. A., Rangel Lozano, C. E. G., Aréstegui Ruiz, F., y Solís Téllez, J. (coords.) (2014). Del asalto al cuartel Madera a la reparación del daño a víctimas de la violencia del pasado. Una experiencia compartida en Chihuahua y Guerrero. México: CESOP-UACM-JP.

Sánchez Serrano, E. (2014). Las políticas de reparación a las víctimas en Atoyac, Guerrero, a partir de la sentencia de la corte Internacional de Derechos Humanos. En E. Sánchez, G. A. Ferrer, C. E. G. Rangel, F. Aréstegui Ruiz, y J. Solís Téllez (coords.), Del asalto al cuartel Madera a la reparación del daño a víctimas de la violencia del pasado. Una experiencia compartida en Chihuahua y Guerrero. pp. 247-294Secretaría de la Presidencia. (1976). México a través de los informes presidenciales. México: Secretaría de la Presidencia. T. 1.

Serrano Migallón, F. (1998). El asilo político en México. México: Porrúa.

Sikkink, K. (1996). Nongovernmental Organizations, Democracy, and Human Rights in Latin America. En T. Farer (Ed.). Beyond Sovereignty. Collectively defending Democracy in the Americas (pp. 150-168). Baltimore: John Hopkins University Press.

Sin Embargo (8 de diciembre de 2015).Organismos internacionales denuncian acoso y difamación contra miembros del GIEI-CIDH. Recuperado de http://www.sinembargo.mx/08-12 2015/1572924?utm source $=$ Relacionados\&utm_medium $=$ Lista\&utm_campaign $=$ SEO

Urrutia, A., y Martínez, F. (16 de noviembre de 2017). Promulga Peña Ley de Desapariciones Forzadas. En La Jornada. Recuperado de http:// www.jornada.unam.mx/ultimas/2017/11/16/promulga-pena-ley-dedesapariciones-forzadas-1670.html

Vicenteño, D. (11 de febrero de 2016). Hay 27 mil 659 desaparecidos; reporte oficial del gobierno. En Excelsior. Recuperado de http://www. excelsior.com.mx/nacional/2016/02/11/1074404. 